\title{
Macrophage migration inhibitory factor: molecular, cellular and genetic aspects of a key neuroendocrine molecule
}

\author{
R P Donn ${ }^{1,3}$ and D W Ray ${ }^{2,3}$ \\ ${ }^{1}$ Arthritis Research Campaign/Epidemiology Unit, University of Manchester, Stopford Building, Oxford Road, Manchester M13 9PT, UK \\ ${ }^{2}$ Endocrine Sciences Research Group, University of Manchester, Stopford Building, Oxford Road, Manchester M13 9PT, UK \\ ${ }^{3}$ Centre for Molecular Medicine, University of Manchester, Stopford Building, Oxford Road, Manchester M13 9PT, UK \\ (Requests for offprints should be addressed to R P Donn; Email: Rachelle@fs1.ser.man.ac.uk)
}

\begin{abstract}
The immunological and neuroendocrine properties of macrophage migration inhibitory factor (MIF) are diverse. In this article we review the known cellular, molecular and genetic properties of MIF that place it as a key regulatory cytokine, acting within both the innate and adaptive immune responses.

The unexpected and paradoxical induction of MIF secretion by low concentrations of glucocorticoids is explored. The role of MIF as a locally acting modulator of glucocorticoid sensitivity within foci of inflammation is also discussed. MIF has no homology with any other pro-inflammatory cytokine and until recently lacked a
\end{abstract}

recognised transmembrane receptor. MIF has also been shown to be directly taken up into target cells and to interact with intracellular signalling molecules, including the Jun activation domain-binding protein Jab-1.

Comprehensive analysis of the MIF gene has identified important functional polymorphisms and a series of genetic studies has revealed both association and linkage of MIF with inflammatory diseases. Altered MIF regulation may therefore be pivotal to acquiring chronic inflammation following an innate immune response.

Journal of Endocrinology (2004) 182, 1-9

\section{Background}

Many aspects of macrophage migration inhibitory factor (MIF) have proved intriguing to researchers over the course of the past 40 years. MIF was originally identified, in 1966, by two groups of researchers studying delayedtype hypersensitivity, as an activity isolated from guinea pig $T$ lymphocytes that was capable of inhibiting the random migration of macrophages (Bloom \& Bennett 1966, David 1966). However, these early experiments used crude conditioned media contaminated with other factors known to affect macrophage movement (interleukin (IL)-4 and interferon- $\gamma$ ).

The human MIF cDNA was finally cloned in 1989 (Weiser et al. 1989), and its genomic localisation to chromosome 22q11.2 later mapped (Budarf et al. 1997). Studies using pure recombinant human MIF and specific neutralising antibodies have shown MIF to be a potent pro-inflammatory cytokine, and a key modulator of immune and inflammatory responses.

An endocrine identity for MIF was proposed when MIF was found in pituitary corticotroph cells, appeared to be in the same dense-core neurosecretory granules as adrenocorticotrophin (ACTH), and was proposed to be co-secreted with ACTH (Nishino et al. 1995). It was proposed that the circulating pool of MIF was derived, to a significant degree, by pituitary secretion, under the control of hypothalamic corticotrophin-releasing hormone. MIF expression was also found in pituitary thyrotroph cells. In addition, it was reported that MIF secretion from macrophages was induced by very low concentrations of glucocorticoid (dexamethasone or hydrocortisone at $10^{-14} \mathrm{M}$ ) in a rodent cell line (Calandra et al. 1995). As MIF was shown to oppose glucocorticoid inhibition of pro-inflammatory cytokine secretion, MIF was proposed to function both as a systemically acting, 'endocrine' cytokine, and also as part of a locally acting, shortfeedback loop limiting the anti-inflammatory actions of glucocorticoids.

More recently, careful studies in human volunteers have failed to demonstrate the same mode of regulation as proposed from the rodent studies. ACTH secretogogues did not alter serum MIF concentrations, and neither did exogenous glucocorticoids (Isidori et al. 2002). 


\section{The human MIF gene}

The genomic organisation of the human MIF gene was reported by Paralkar \& Wistow in 1994. They described a 'remarkably small' gene of less than $1 \mathrm{~kb}$, identified from the screening of a human placenta genomic library. The human MIF gene has three exons of 205, 173 and $183 \mathrm{bp}$. These are separated by two introns of 189 and $95 \mathrm{bp}$ (EMBL ID: Homo Sapiens Macrophage Migration Inhibitory Factor (HSMIF) http://www.ebi.ac.uk/cgi-bin/ emblfetch/).

Only a single functional MIF gene exists in humans, unlike in mice where several processed (intronless) pseudogenes have been described (Bozza et al. 1995, Kozak et al. 1995, Mitchell et al. 1995). The MIF gene of other mammals is similarly short and present in one expressed copy per haploid genome.

The clones sequenced by Paralkar \& Wistow (1994) identified $250 \mathrm{bp}$ of $3^{\prime}$ untranslated region and $1 \mathrm{~kb}$ of $5^{\prime}$ flanking region. Primer extension and $5^{\prime}$ rapid amplification of cDNA ends were used to map the transcription start site, and identified a single site $97 \mathrm{bp}$ upstream from the initiator methionine, in a TATA-less promoter (Paralkar \& Wistow 1994). These approaches cannot exclude the presence of additional transcription start sites, and the anatomy of the MIF promoter, consisting of abundant GC content, and no TATA box, would suggest the presence of multiple transcription start sites. However, analysis of mRNA harvested from multiple tissues, heart, brain, placenta, lung, liver, skeletal muscle, kidney and pancreas, by Northern blot analysis identified a single transcript (of approximately 800 nucleotides). Certain tissues, such as kidney and brain, showed high MIF expression, whilst others, including muscle and pancreas, had relatively low expression (Paralkar \& Wistow 1994).

\section{Polymorphism of the human MIF gene}

The presence of raised MIF protein concentrations within the serum, plasma or tissue in several diseases of an endocrine or chronic inflammatory basis (Niino et al. 2000, Yabunaka et al. 2000, de Jong et al. 2001, Matsumoto \& Kanmatsuse 2001, Murakami et al. 2001, Donn et al. 2002, Meazza et al. 2002, Morand et al. 2002, Sakai et al. 2003), suggests a role for MIF in pathogenesis. Alternatively, increased expression of MIF in these sites could be consequential, rather than causative. In an attempt to address this conundrum, variation of the MIF gene was determined. The identification of any polymorphic variants of MIF would allow future comparisons of specific combinations of these genetic changes (or genotypes) with diseased and non-diseased individuals to be undertaken. If a genetic basis to altered endogenous MIF protein production were found to underlie the disease states this would be important evidence for a central contributory role of MIF in the pathogenesis of the disease.
Donn et al. (2002) used denaturing high performance liquid chromatography (WAVE machine, Transgenomic, Crewe, UK) to look for variations across the whole of the MIF gene and $1 \mathrm{~kb}$ of the $5^{\prime}$ flanking region. This screen was performed in 32 healthy, normal UK Caucasian individuals and in 96 children with juvenile idiopathic arthritis (JIA), a chronic inflammatory disease in which raised MIF protein concentrations had been described (Meazza et al. 2002). Four polymorphic positions were found. These were all seen both in the healthy volunteers and subjects with JIA. The CATT repeat element, originally documented by Paralkar \& Wistow (1994), was found to be polymorphic with five to eight alleles existing. The eight-allele repeat is found at only very low allele frequency in UK Caucasians. Also, within the $5^{\prime}$ flanking region, a single nucleotide polymorphism (SNP) at nucleotide position $-173(\mathrm{G}$ to $\mathrm{C}$ ) (relative to HSMIF) was seen. Two intronic polymorphisms at nucleotide positions +254 ( $\mathrm{T}$ to $\mathrm{C}$ ) and at +656 (C to $\mathrm{G}$ ) were also identified. These polymorphic positions and the allele frequencies taken from the study of 342 UK healthy controls are shown in Fig. 1. Baugh et al. (2002), having sequenced the $5^{\prime}$ flanking region of MIF in six normal individuals and six rheumatoid arthritis patients, also described the tetranucleotide CATT repeat element which begins at position -794 .

\section{Linkage disequilibrium and haplotype tagging of MIF SNPs in UK Caucasians}

Where more than one SNP has been defined in a gene it is important to study the extent of linkage disequilibrium (allelic association) that exists. This can be informative as it potentially allows the study of haplotypes, or chromosomal segments that are transmitted en bloc. This should be determined within a control population initially and then reassessed for any disease group studied.

Furthermore, this allows genotyping of particular SNPs to be informative by predicting a haplotype containing SNPs at other positions. This results in less genotyping, so reducing both the cost and the through-put time. The SNPs that allow the largest number of haplotypes to be captured by the minimum number of SNPs are called haplotype tagging SNPs or htSNPs (Johnson et al. 2001).

Evidence for strong linkage disequilibrium was found for the four polymorphic positions of MIF in the UK Caucasian population investigated by Donn et al. (2002), specifically for the rare alleles at each polymorphic position.

htSNPs of MIF have been determined in the UK Caucasian controls and are shown in Table 1. This indicates that, in any study using UK Caucasian as controls, $93 \cdot 1 \%$ of the MIF haplotypes occurring at a frequency of $>1 \%$ can be determined by genotyping just the CATT and the +656 polymorphisms. 
$\begin{array}{llll}\text { CATT }_{(5-8)} & -173 \mathrm{G} / \mathrm{C} & +254 \mathrm{~T} / \mathrm{C} & +656 \mathrm{C} / \mathrm{G}\end{array}$

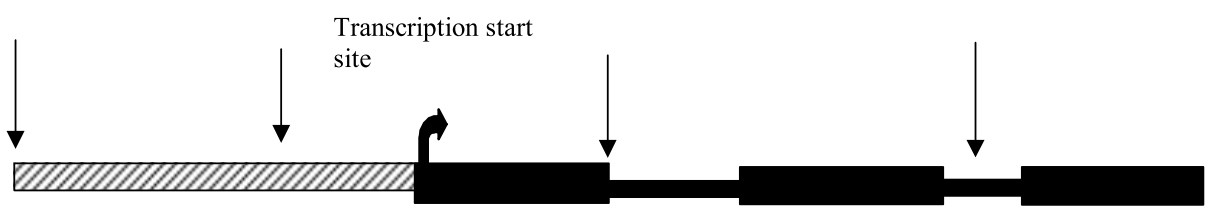

$\begin{array}{llllll}\text { Promoter } & \text { Exon } 1 & \text { Intron 1 } & \text { Exon } 2 & \text { Intron 2 } & \text { Exon } 3\end{array}$
$5-25.3 \%$
G $-\mathbf{8 8 . 0} \%$
T $-\mathbf{8 8 . 8 \%}$
C $-86.3 \%$
$6-65.6 \%$
$\mathrm{C}-\mathbf{1 2 . 0 \%}$
$\mathrm{C}-\mathbf{1 1 . 2 \%}$
$\mathrm{G}-\mathbf{1 3 . 7 \%}$

$7-8.8 \%$

$8-0.3 \%$

Figure 1 MIF gene polymorphisms: allele frequencies in UK Caucasian controls $(n=342)$.

\section{Genetic polymorphism of MIF and association with disease}

Following the description of genetic polymorphism of MIF a number of disease association studies have been described. Baugh et al. (2002) showed that the short CATT repeat (CATT5) was associated with less severe rheumatoid arthritis in a cohort of hospital-derived patients from Wichita, KA, USA.

Barton et al. (2003) found an association of a specific MIF promoter haplotype composed of CATT7-MIF$173 * \mathrm{C}$ and susceptibility to adult inflammatory polyarthritis. The majority of this cohort developed rheumatoid arthritis. When outcome measures of disease severity were considered however, no association with MIF polymorphisms were seen (Barton et al. 2003). These differences may be explained by variation in case ascertainment but, taken together, a pathogenic role for MIF is supported. The same promoter haplotype (CATT7-MIF-173*C) has been shown to be both linked and associated with JIA (Donn et al. 2004). JIA is the commonest chronic arthritis to commence before the age of 16 years. It encompasses seven clinically distinct subgroups, all of which share the feature of chronic synovitis (Petty et al. 1998).

The MIF- $173^{*} \mathrm{C}$ polymorphism has been shown to be positively associated with sarcoidosis in biopsy-proven erythema nodosum in a Spanish population (Amoli et al.

Table 1 MIF haplotype frequencies and haplotype tagging SNPs in UK Caucasian controls

\begin{tabular}{|c|c|c|c|c|c|}
\hline CATT* & MIF-173 & MIF+ 254 & MIF + 656* & $n$ & $\%$ Frequency \\
\hline 6 & G & $\mathbf{T}$ & C & 191 & $60 \cdot 1$ \\
\hline 5 & G & $\mathbf{T}$ & C & 66 & $20 \cdot 8$ \\
\hline 6 & G & $\mathbf{T}$ & G & 16 & 5 \\
\hline 7 & C & C & G & 16 & 5 \\
\hline 6 & $\mathrm{C}$ & $\mathrm{C}$ & G & 9 & $2 \cdot 7$ \\
\hline 5 & G & $\mathbf{T}$ & G & 7 & $2 \cdot 2$ \\
\hline 7 & C & $\mathrm{T}$ & G & 5 & $1 \cdot 6$ \\
\hline 5 & C & C & G & 4 & $1 \cdot 3$ \\
\hline \multirow[t]{2}{*}{6} & $\mathrm{C}$ & $\mathrm{T}$ & G & 4 & $1 \cdot 3$ \\
\hline & & & & 318 & 100 \\
\hline
\end{tabular}

*htSNPs.

htSNPs were investigated in 342 normal Caucasian individuals. Only haplotypes occurring at a frequency of $>1 \%$ in this population were considered $(n=318)$. Of these $93 \cdot 1 \%$ can be assigned by genotyping for both the CATT repeat and the MIF+656 polymorphism only. The haplotypes captured are shown in bold. 
2002). This same promoter polymorphism of MIF has also been shown to be predictive of disease outcome in patients with systemic onset JIA, a particularly severe onset type of JIA (De Benedetti et al. 2003a). More specifically, De Benedetti et al. (2003a) found that carriage of the MIF-173*C polymorphism was correlated with raised serum and synovial fluid levels of MIF protein, and to be predictive of the duration of response to intra-articular injection of triamcinolone hexacetonide (TXA). Those individuals with a mutant allele at -173 (MIF-173*C) relapsed more quickly than individuals with the MIF173GG wild-type genotype (De Benedetti et al. 2003a). This effect has now also been demonstrated for the response to intra-articular TXA injection in patients with an oligoarticular phenotype ( $\leq$ four joints affected at presentation), the commonest presentation of JIA. Again, the duration of clinical response to the steroid treatment (months with no clinical evidence of synovitis) was significantly shorter in patients carrying a MIF- $173 * \mathrm{C}$ allele (median 6 months; range 1-39) than in the MIF173*GG homozygotes (median 9 months, range 2-62) (De Benedetti et al. 2003b).

\section{Promoter activity of MIF and the significance of the known polymorphic variants}

Two groups (Baugh et al. 2002, Donn et al. 2002, 2004) have confirmed the putative promoter identified by Paralkar \& Wistow (1994) in several cell lines. Baugh et al. (2002) described variation in reporter gene luciferase activity for the different CATT alleles, with the CATT5 allele being shown to have the lowest level of basal and stimulated MIF-promoter activity in human lung epithelial (A549) and fibroblast cell lines. Donn et al. (2002) have shown that the MIF-173G/C polymorphism regulates promoter activity and that higher reporter gene luciferase activity is found for the MIF- $173^{*} \mathrm{C}$ in the human $\mathrm{T}$ lymphoblast cell line (CEMC7A), whilst in human lung epithelial cells (A549s) MIF-173*G allele has higher luciferase promoter activity. Importantly, there is a functional interaction between the CATT repeats and the -173 SNP. Constructs of MIF-173*C with CATT5, 6 and 7 length repeats and, similarly, a series of constructs with MIF-173*G together with CATT5, 6 and 7 length repeats were studied. Here, again, a cell type-specific difference was found. In a $\mathrm{T}$ lymphoblast cell line increasing CATT repeat with the MIF- $173 * \mathrm{C}$ polymorphism significantly increased the luciferase promoter activity. No effect of CATT repeat length with the MIF- $173^{*} \mathrm{G}$ was seen. In the A549 cells again increasing CATT repeat length significantly increased luciferase activity of the MIF-173*C constructs. However, increasing CATT repeat length reduced the luciferase activity of the MIF$173 * G$ constructs (Donn et al. 2004). This work suggests that different transcription factors, occurring within

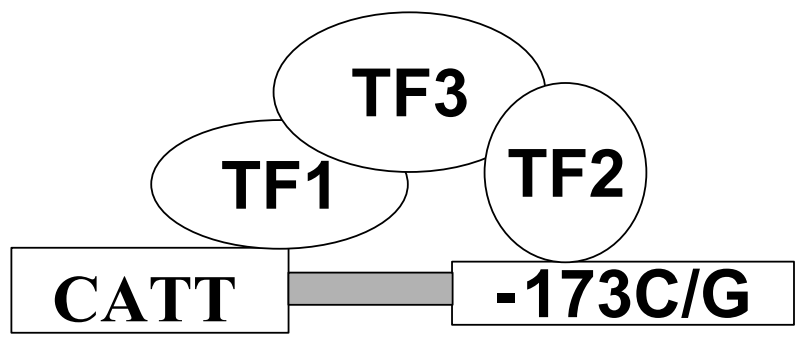

Figure 2 MIF promoter polymorphisms and transcription factor binding. Hypothesis: functional interaction between the CATT repeat and the MIF- $173^{*} \mathrm{G} / \mathrm{C}$ polymorphism is dependent upon the transcription factors (TFs) that are able to bind. The available pool of TFs is influenced by the cell type.

different cell types by binding to the CATT and MIF$173^{*} \mathrm{G} / \mathrm{C}$ polymorphic sites, alter MIF promoter activity (Fig. 2). Such cell type-specific interactions with naturally occurring gene promoter polymorphisms are well described, for example in prolactin, IL-10 and IL-6, and likely reflect the differential expression of transcription factors, and co-factors between cell types (Fishman et al. 1998, Stevens et al. 2001, Kay et al. 2002).

In addition to basal promoter activity, MIF promoter regulation has also been studied. There are sequences within the proximal promoter with resemblance to cAMP response elements, and indeed forskolin has been shown to stimulate the activity of both endogenous and transfected MIF genes in the mouse pituitary cell line, AtT20 (Waeber et al. 1998). However, analysis of the regulatory elements required for tissue-specific, and appropriately regulated MIF transcription, and the influence of gene polymorphism on such expression is still lacking. In particular, the peculiar mode of glucocorticoid up-regulation of MIF expression requires explanation, and is of major clinical importance as glucocorticoids are widely used to treat human inflammatory disease.

It is increasingly recognised that important gene regulatory elements can map at distant sites both $5^{\prime}$ and $3^{\prime}$ to the coding region of the gene (Nobrega et al. 2003, Ho et al. 2004). Furthermore, the chromatin environment of different cell types could dramatically influence the amount of MIF protein produced. It will therefore be necessary to look comprehensively at the genomic region surrounding MIF, for such regulatory sites, and to study them within a native chromatin environment.

\section{MIF protein}

The product of the MIF gene is a small 115 amino acid protein of molecular mass $12.5 \mathrm{kDa}$. The protein is highly conserved and homologues exist in the plant Arabidopsis thaliana, nematodes and vertebrates (Esumi et al. 1998). The sequence homology between human and mouse MIF is $89 \%$. MIF has no significant sequence homology to any 
other protein. Also, the three-dimensional structure of MIF is unlike any other cytokine or pituitary hormone. The only proteins that share partial structural similarity with MIF are the enzymes D-dopachrome tautomerase (Sugimoto et al. 1999), found in humans (and mapping close to MIF on chromosome 22q11.2), and 4-oxalocrotonate tautomerase, 5-carboxymethyl-2hydroxymuconate isomerase and chorismate mutase, of microbial origin (Chook et al. 1994, Subramanya et al. 1996).

The crystal structure of MIF, to $1.8 \mathrm{~A}$ resolution, showed MIF to exist as a trimer (Sugimoto et al. 1996, Sun et al. 1996, Suzuki et al. 1996, Taylor et al. 1999). However, it is currently not known whether this represents the true, physiological state of MIF protein, as studies have suggested bioactive MIF monomers or dimers (Mischke et al. 1998). Each monomer of MIF is known to be composed of the following: two antiparallel $\alpha$-helices $(\alpha 1$ and $\alpha 2)$ and six $\beta$ strands $(\beta 1-\beta 6)$. Four of the six $\beta$ strands $(\beta 1, \beta 2, \beta 4, \beta 5)$ form a $\beta$-pleated sheet above which the two $\alpha$-helices rise. This composition is very similar to the peptide-binding domain of a major histocompatibility complex molecule (Bjorkman et al. 1987). The remaining two $\beta$ strands have been shown to interact with the $\beta$ sheets of adjacent MIF subunits in a trimer. When formed as a trimeric complex the three $\beta$ sheets form a barrel containing a solvent-accessible channel which runs through the centre of the protein.

\section{Mechanisms of MIF regulation and action}

\section{Glucocorticoid regulation of MIF secretion}

The initial report of glucocorticoid induction of MIF secretion was exciting, as this was an extremely unusual mode of regulation for a pro-inflammatory cytokine (Calandra et al. 1995). A number of anti-inflammatory cytokines are known to be up-regulated by glucocorticoid, notably IL-10, but pro-inflammatory cytokines, e.g. tumour necrosis factor- $\alpha$ (TNF $\alpha$ ) and IL-1 are typically suppressed (Elenkov \& Chrousos 2002). Further analysis in rodents has suggested that organ MIF protein content was induced by parenteral glucocorticoid administration, suggesting a direct effect on MIF production, as well as on MIF secretion. Interestingly, there was no concordant increase in MIF mRNA, suggesting an effect on protein translation (Fingerle-Rowson et al. 2003). Such local up-regulation of MIF production by glucocorticoids has been proposed as a counter-regulatory mechanism for glucocorticoid immunosuppressive actions (Donnelly \& Bucala 1997, Leech et al. 1999, Gregersen \& Bucala 2003, Morand et al. 2003). Careful studies in human volunteers have not confirmed the regulation of circulating MIF by glucocorticoids (Isidori et al. 2002), and this phenomenon requires further study to determine if it extends across the species barrier.
MIF appears to circulate in healthy volunteers at relatively high serum concentrations $(2-6 \mathrm{ng} / \mathrm{ml})$ and at such concentrations a direct effect of MIF on immune cells, or on glucocorticoid activity, might be expected. Intriguingly, a circadian rhythm of MIF has been described in humans, with a late morning peak $(0700 \mathrm{~h})$ coincidental with that of cortisol (Petrovsky et al. 2003).

Much higher circulating concentrations of MIF are found in inflammatory diseases, and in response to experimental endotoxaemia or inflammation in animal models (reviewed in Fingerle-Rowson \& Bucala 2001, Baugh \& Bucala 2002, Gregersen \& Bucala 2003).

\section{MIF effects on glucocorticoid action}

MIF is a pleiotropic molecule. It is a pro-inflammatory cytokine, an anterior pituitary hormone, and it possesses enzymatic activity. Therefore, several molecular pathways are likely to mediate its actions.

A number of studies have addressed the interaction between MIF and glucocorticoid action. Glucocorticoids suppress the increase in cytokine secretion from macrophages induced by lipopolysaccharide exposure, and exposure to MIF prevents this effect (Bernhagen et al. 1993, Calandra et al. 2000). In addition, MIF opposes the anti-proliferative effects of glucocorticoids on $\mathrm{T}$ lymphocytes, and similarly the glucocorticoid suppression of IL-2 from the same cells (Bacher et al. 1996). In vivo studies have shown that MIF opposes the anti-arthritic effects of glucocorticoids in animal models of arthritis (Mikulowska et al. 1997, Leech et al. 1998, 2000, Santos et al. 2001). The underlying mechanism for such antagonism is not known, but MIF is known not to affect the nerve factor $\kappa \mathrm{B}(\mathrm{NF \kappa B})$ signalling pathway. However, MIF does act to cause prolonged activation of ERK and p38 MAP kinases, which may result in molecular antagonism of the glucocorticoid receptor (GR), although no change in GR expression or affinity have been found (Daun \& Cannon 2000).

In an attempt to identify intracellular proteins that interact with MIF, Kleemann et al. (2000) used full-length human MIF cDNA as a bait in a yeast two-hybrid screen against a human brain cDNA library. This identified the Jun activation domain-binding protein 1 (JAB-1). Co-immunoprecipitation and pull-down experiments confirmed the specific MIF-JAB-1 association. JAB-1 was originally described as a co-activator of the transcription factor AP-1. Subsequently, multiple actions of JAB-1 have been documented, including regulation of $\mathrm{p} 27^{\mathrm{Kip} 1}$ degradation, binding to glucocorticoid and progesterone receptors and interaction with p53. Kleeman et al. (2000) used luciferase reporter and gel shift assays to show that endogenous and exogenous MIF inhibited JAB-1-induced AP-1 transcriptional activity, but did not interfere with NFKB activity. Similarly, recombinant MIF inhibited JAB-1-stimulated and TNF-induced MAP 


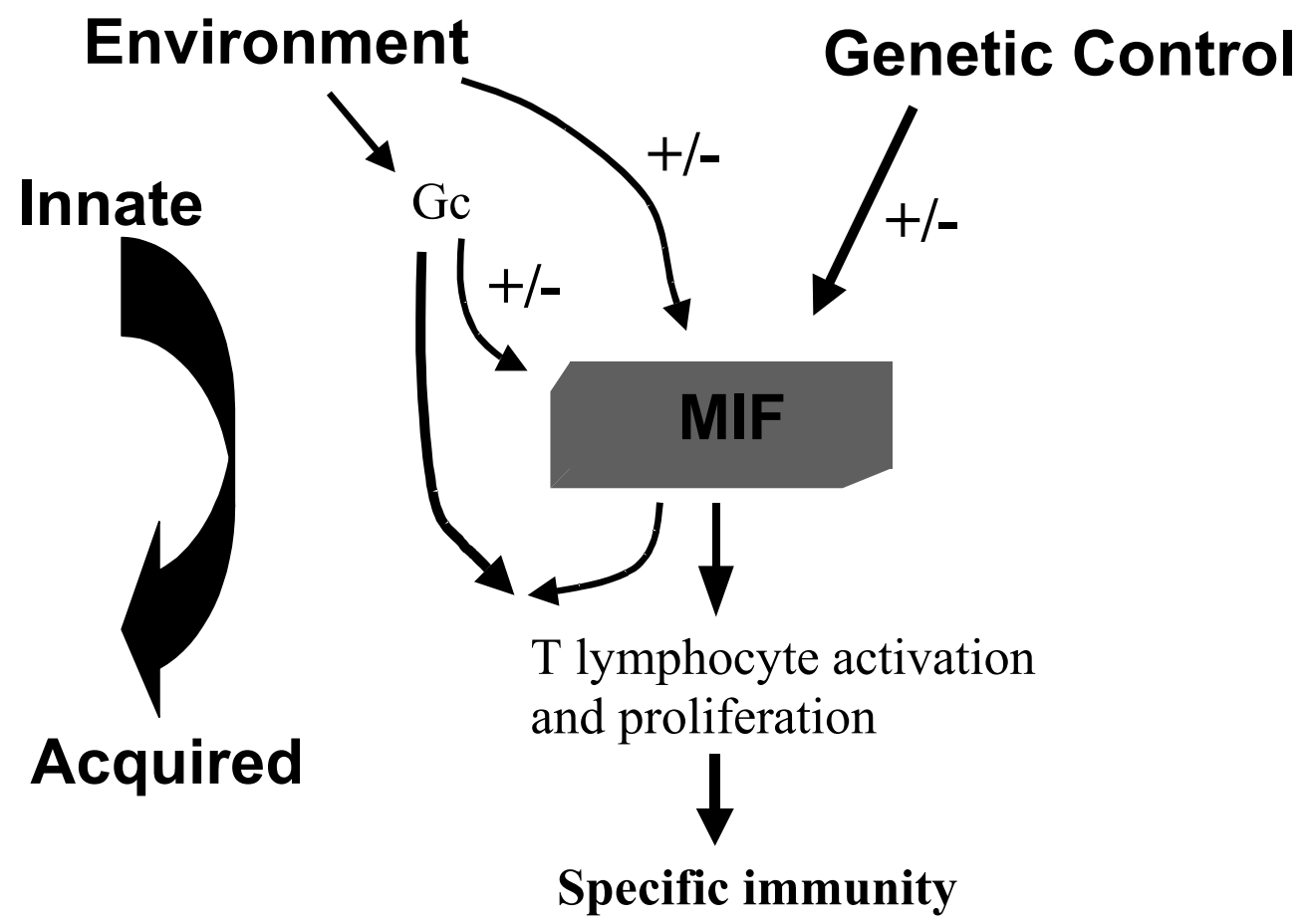

Figure 3 Schematic representation of MIF as a key mediator of the immune response.

kinase 8 activity. This action of MIF is counterintuitive, as up-regulation of AP-1 activity is typically seen in response to pro-inflammatory cytokine action (Kleemann et al. 2000).

The MIF-JAB-1 complex was found to localise within the cytosol, near the peripheral plasma membrane. This complex was also found to occur following uptake of MIF into target cells by non-receptor-mediated pathways.

\section{Mechanisms of MIF actions in monocytes/macrophages}

MIF is known to lack a classic N-terminal leader sequence or an internal signal sequence for import into the endoplasmic reticulum. Furthermore, Flieger et al. (2003), using endotoxin-stimulated THP-1 monocytes, showed that MIF does not enter the endoplasmic reticulum and that MIF secretion occurs via a non-classical export route. Glyburide and probenicid, but no other typical inhibitors of the non-classical protein export, strongly inhibit MIF secretion. This indicates that the export of MIF involves an ABCA1 transporter (Flieger et al. 2003).

As the actions of MIF appear to involve interactions with intracellular proteins, recent studies identifying a transmembrane receptor for MIF are interesting. Leng et al. (2003), however, using expression cloning and functional analysis found CD74 (antigen-associated invariant chain Ii) to be a high-affinity membrane-binding protein for MIF. MIF was shown to bind to amino acids 109-149 of a recombinant soluble form of CD74 with a dissociation constant of $\sim 9 \times 10^{-9} \mathrm{kDa}$, as measured by surface plasmon resonance (BIAcore analysis). The binding appears necessary for the MIF-induced activation of the extracellular MAP kinase cascade, cell proliferation and prostaglandin E2 production (Leng et al. 2003).

Monocytes and macrophages constitutively express large quantities of MIF. This is unusual for a cytokine. When microbial pathogens bind to their recognition receptors, macrophages become activated and release a panoply of different cytokines that initiate the host's innate and adaptive immune responses (Fig. 3). In an elegant series of experiments, Roger et al. (2001) showed that mouse macrophages transfected with antisense MIF mRNA, and macrophages from $\mathrm{MIF}^{-1-}$ mice, were hyporesponsive to endotoxin (lipopolysaccharide) and gram-negative bacteria, as measured by TNF $\alpha$ and IL- 6 production. The MIF-deficient cells were found to have reduced mRNA and protein expression of a specific toll-like receptor, toll-like receptor 4 (TLR4). Electromobility shift assays and promoter truncation/mutation analysis found that the lack of MIF expression impaired basal PU.1 transcription factor binding to the mouse TLR 4 gene. This in turn reduced TLR 4 protein expression and resulted in hyporesponsiveness to lipopolysaccharide and gram-negative bacteria. Inhibition of MIF activity may, therefore, be of therapeutic benefit for individuals with gram-negative septic shock. 


\section{Conclusions}

MIF has several unusual properties for a pro-inflammatory cytokine. It circulates in healthy individuals at relatively high concentrations (Petrovsky et al. 2003), and is expressed in many normal tissues, including the pituitary (Paralkar \& Wistow 1994, Nishino et al. 1995). Expression of MIF is augmented in inflammation, influenced by neuroendocrine mechanisms acting on the pituitary and also, paradoxically, is increased by exposure to low concentrations of glucocorticoids. The actions of MIF seem to be mediated by activation of cellular ERK activity, and JAB-1, but it remains unclear whether a transmembrane receptor or a cellular uptake mechanism is the primary means of signal transduction across the membrane. Although the MIF gene structure is highly conserved there appear to be differences between rodents and humans in terms of glucocorticoid induction of MIF secretion, perhaps implying that this mechanism is not conserved across species.

MIF is an important mediator of the innate immune response (Roger et al. 2001). Local MIF production may influence recruitment of elements of the acquired immune response (Bacher et al. 1996, Santos et al. 2001). Such a 'gatekeeper' role may explain why genetic variation of MIF is beginning to be found to be important in susceptibility to several complex inflammatory diseases. Understanding MIF biology may lead to new insights into the aetiology of many chronic, disabling human disorders and, also, to the development of novel therapeutic approaches to treat such conditions.

\section{References}

Amoli MM, Donn RP, Thomson W, Hajeer AH, Garcia-Porrua C, Lueiro M, Ollier WE \& Gonzalez-Gay MA 2002 Macrophage migration inhibitory factor gene polymorphism is associated with sarcoidosis in biopsy proven erythema nodosum. Journal of Rheumatology 29 1671-1673.

Bacher M, Metz CN, Calandra T, Mayer K, Chesney J, Lohoff M, Gemsa D, Donnelly T \& Bucala R 1996 An essential regulatory role for macrophage migration inhibitory factor in T-cell activation. PNAS 93 7849-7854.

Barton A, Lamb R, Symmons D, Silman A, Thomson W, Worthington J \& Donn R 2003 Macrophage migration inhibitory factor (MIF) gene polymorphism is associated with susceptibility to but not severity of inflammatory polyarthritis. Genes and Immunity 4 487-491.

Baugh JA \& Bucala R 2002 Macrophage migration inhibitory factor. Critical Care Medicine 30 S27-S35.

Baugh JA, Chitnis S, Donnelly SC, Monteiro J, Lin X, Plant BJ, Wolfe F, Gregersen PK \& Bucala R 2002 A functional promoter polymorphism in the macrophage migration inhibitory factor (MIF) gene associated with disease severity in rheumatoid arthritis. Genes and Immunity 3 170-176.

Bernhagen J, Calandra T, Mitchell RA, Martin SB, Tracey KJ, Voelter W, Manogue KR, Cerami A \& Bucala R 1993 MIF is a pituitary-derived cytokine that potentiates lethal endotoxaemia. Nature 365 756-759.

Bjorkman PJ, Saper MA, Samraoui B, Bennett WS, Strominger JL \& Wiley DC 1987 The foreign antigen binding site and T cell recognition regions of class I histocompatibility antigens. Nature 329 $512-518$.

Bloom BR \& Bennett B 1966 Mechanism of a reaction in vitro associated with delayed-type hypersensitivity. Science 153 80-82.

Bozza M, Kolakowski LF Jr, Jenkins NA, Gilbert DJ, Copeland NG, David JR \& Gerard C 1995 Structural characterization and chromosomal location of the mouse macrophage migration inhibitory factor gene and pseudogenes. Genomics 27 412-419.

Budarf M, McDonald T, Sellinger B, Kozak C, Graham C \& Wistow G 1997 Localization of the human gene for macrophage migration inhibitory factor (MIF) to chromosome 22q11·2. Genomics 39 235-236.

Calandra T, Bernhagen J, Metz CN, Spiegel LA, Bacher M, Donnelly T, Cerami A \& Bucala R 1995 MIF as a glucocorticoid-induced modulator of cytokine production. Nature 377 68-71.

Calandra T, Echtenacher B, Roy DL, Pugin J, Metz CN, Hultner L, Heumann D, Mannel D, Bucala R \& Glauser MP 2000 Protection from septic shock by neutralization of macrophage migration inhibitory factor. Nature Medicine 6 164-170.

Chook YM, Gray JV, Ke H \& Lipscomb WN 1994 The monofunctional chorismate mutase from Bacillus subtilis. Structure determination of chorismate mutase and its complexes with a transition state analog and prephenate, and implications for the mechanism of the enzymatic reaction. Journal of Molecular Biology 240 476-500.

Daun JM \& Cannon JG 2000 Macrophage migration inhibitory factor antagonizes hydrocortisone-induced increases in cytosolic IkappaBalpha. American Journal of Physiology - Regulatory, Integrative and Comparative Physiology 279 R1043-R1049.

David JR 1966 Delayed hypersensitivity in vitro: its mediation by cell-free substances formed by lymphoid cell-antigen interaction. PNAS 56 72-77.

De Benedetti F, Meazza C, Vivarelli M, Rossi F, Pistorio A, Lamb R, Lunt M, Thomson W, Ravelli A, Donn R et al. 2003a Functional and prognostic relevance of the -173 polymorphism of the macrophage migration inhibitory factor gene in systemic-onset juvenile idiopathic arthritis. Arthritis and Rheumatism 48 1398-1407.

De Benedetti F, Vivarelli M, Lamb R, Meazza C, Muratori F, Cioschi S, Cortis E, Ravelli A, Martini A \& Donn R 2003b Association of the $-173 \mathrm{SNP}$ of the macrophage migration inhibitory factor (MIF) gene with response to intra-articular glucocorticoids in oligoarticular JIA. Arthritis and Rheumatism 48 S254.

Donn RP, Alourfi Z, De Benedetti F, Meazza C, Zeggini E, Lunt M, Stevens A, Shelley E, Lamb R, Ollier WE et al. 2002 Mutation screening of the macrophage migration inhibitory factor gene: positive association of a functional polymorphism of macrophage migration inhibitory factor with juvenile idiopathic arthritis. Arthritis and Rheumatism 46 2402-2409.

Donn RP, Alourfi Z, Zeggini E, Lamb R, Jury F, Lunt M, BPRG Study Group, Meazza C, De Benedetti F, Thomson W et al. 2004 A functional promoter haplotype of macrophage migration inhibitory factor (MIF) is linked and associated with juvenile idiopathic arthritis. Arthritis and Rheumatism 50 1604-1610.

Donnelly SC \& Bucala R 1997 Macrophage migration inhibitory factor: a regulator of glucocorticoid activity with a critical role in inflammatory disease. Molecular Medicine Today 3 502-507.

Elenkov IJ \& Chrousos GP 2002 Stress hormones, proinflammatory and antiinflammatory cytokines, and autoimmunity. Annals of the New York Academy of Sciences 966 290-303.

Esumi N, Budarf M, Ciccarelli L, Sellinger B, Kozak CA \& Wistow G 1998 Conserved gene structure and genomic linkage for D-dopachrome tautomerase (DDT) and MIF. Mammalian Genome 9 753-757.

Fingerle-Rowson GR \& Bucala R 2001 Neuroendocrine properties of macrophage migration inhibitory factor (MIF). Immunology and Cell Biology 79 368-375. 
Fingerle-Rowson G, Koch P, Bikoff R, Lin X, Metz CN, Dhabhar FS, Meinhardt A \& Bucala R 2003 Regulation of macrophage migration inhibitory factor expression by glucocorticoids in vivo. American Journal of Pathology 162 47-56.

Fishman D, Faulds G, Jeffery R, Mohamed-Ali V, Yudkin JS, Humphries S \& Woo P 1998 The effect of novel polymorphisms in the IL-6 gene on IL-6 transcription and plasma IL-6 levels, and an association with systemic-onset juvenile chronic arthritis. Journal of Clinical Investigation 102 1369-1376.

Flieger O, Engling A, Bucala R, Lue H, Nickel W \& Bernhagen J 2003 Regulated secretion of macrophage migration inhibitory factor is mediated by a non-classical pathway involving an $\mathrm{ABC}$ transporter. FEBS Letters $\mathbf{5 5 1}$ 78-86.

Gregersen PK \& Bucala R 2003 Macrophage migration inhibitory factor, MIF alleles, and the genetics of inflammatory disorders: incorporating disease outcome into the definition of phenotype. Arthritis and Rheumatism 48 1171-1176.

Ho Y, Liebhaber SA \& Cooke NE 2004 Activation of the human GH gene cluster: roles for targeted chromatin modification. Trends in Endocrinology and Metabolism 15 40-45.

Isidori AM, Kaltsas GA, Korbonits M, Pyle M, Gueorguiev M, Meinhardt A, Metz C, Petrovsky N, Popovic V, Bucala R et al. 2002 Response of serum macrophage migration inhibitory factor levels to stimulation or suppression of the hypothalamo-pituitaryadrenal axis in normal subjects and patients with Cushing's disease. Journal of Clinical Endocrinology and Metabolism 87 1834-1840.

Johnson GC, Esposito L, Barratt BJ, Smith AN, Heward J, Di Genova G, Ueda H, Cordell HJ, Eaves IA, Dudbridge F et al. 2001 Haplotype tagging for the identification of common disease genes. Nature Genetics 29 233-237.

de Jong YP, Abadia-Molina AC, Satoskar AR, Clarke K, Rietdijk ST, Faubion WA, Mizoguchi E, Metz CN, Alsahli M, ten Hove T et al. 2001 Development of chronic colitis is dependent on the cytokine MIF. Nature Immunology 2 1061-1066.

Kay R, Doherty M, Furrie E, Sankaran D, Hutchinson I \& Paterson J 2002 Inherited haplotypes of the interleukin-10 promoter differentially regulate gene transcription. Arthritis and Rheumatism $\mathbf{4 2}$ S177.

Kleemann R, Hausser A, Geiger G, Mischke R, Burger-Kentischer A, Flieger O, Johannes FJ, Roger T, Calandra T, Kapurniotu A et al. 2000 Intracellular action of the cytokine MIF to modulate AP-1 activity and the cell cycle through Jab1. Nature 408 211-216.

Kozak CA, Adamson MC, Buckler CE, Segovia L, Paralkar V \& Wistow G 1995 Genomic cloning of mouse MIF (macrophage inhibitory factor) and genetic mapping of the human and mouse expressed gene and nine mouse pseudogenes. Genomics 27 405-411.

Leech M, Metz C, Santos L, Peng T, Holdsworth SR, Bucala R \& Morand EF 1998 Involvement of macrophage migration inhibitory factor in the evolution of rat adjuvant arthritis. Arthritis and Rheumatism 41 910-917.

Leech M, Metz C, Hall P, Hutchinson P, Gianis K, Smith M, Weedon H, Holdsworth SR, Bucala R \& Morand EF 1999 Macrophage migration inhibitory factor in rheumatoid arthritis: evidence of proinflammatory function and regulation by glucocorticoids. Arthritis and Rheumatism 42 1601-1608.

Leech M, Metz C, Bucala R \& Morand EF 2000 Regulation of macrophage migration inhibitory factor by endogenous glucocorticoids in rat adjuvant-induced arthritis. Arthritis and Rheumatism 43 827-833.

Leng L, Metz CN, Fang Y, Xu J, Donnelly S, Baugh J, Delohery T, Chen Y, Mitchell RA \& Bucala R 2003 MIF signal transduction initiated by binding to CD74. Journal of Experimental Medicine 197 1467-1476.

Matsumoto K \& Kanmatsuse K 2001 Increased production of macrophage migration inhibitory factor by $\mathrm{T}$ cells in patients with IgA nephropathy. American Journal of Nephrology 21 455-464.
Meazza C, Travaglino P, Pignatti P, Magni-Manzoni S, Ravelli A, Martini A \& De Benedetti F 2002 Macrophage migration inhibitory factor in patients with juvenile idiopathic arthritis. Arthritis and Rheumatism 46 232-237.

Mikulowska A, Metz CN, Bucala R \& Holmdahl R 1997 Macrophage migration inhibitory factor is involved in the pathogenesis of collagen type II-induced arthritis in mice. Journal of Immunology 158 5514-5517.

Mischke R, Kleemann R, Brunner H \& Bernhagen J 1998 Cross-linking and mutational analysis of the oligomerization state of the cytokine macrophage migration inhibitory factor (MIF). FEBS Letters 427 85-90.

Mitchell R, Bacher M, Bernhagen J, Pushkarskaya T, Seldin MF \& Bucala R 1995 Cloning and characterization of the gene for mouse macrophage migration inhibitory factor (MIF). Journal of Immunology 154 3863-3870.

Morand EF, Leech M, Weedon H, Metz C, Bucala R \& Smith MD 2002 Macrophage migration inhibitory factor in rheumatoid arthritis: clinical correlations. Rheumatology 41 558-562.

Morand EF, Bucala R \& Leech M 2003 Macrophage migration inhibitory factor: an emerging therapeutic target in rheumatoid arthritis. Arthritis and Rheumatism 48 291-299.

Murakami H, Akbar SM, Matsui H \& Onji M 2001 Macrophage migration inhibitory factor in the sera and at the colonic mucosa in patients with ulcerative colitis: clinical implications and pathogenic significance. European Journal of Clinical Investigation 31 337-343.

Niino M, Ogata A, Kikuchi S, Tashiro K \& Nishihira J 2000 Macrophage migration inhibitory factor in the cerebrospinal fluid of patients with conventional and optic-spinal forms of multiple sclerosis and neuro-Behcet's disease. Journal of the Neurological Sciences 179 127-131.

Nishino T, Bernhagen J, Shiiki H, Calandra T, Dohi K \& Bucala R 1995 Localization of macrophage migration inhibitory factor (MIF) to secretory granules within the corticotrophic and thyrotrophic cells of the pituitary gland. Molecular Medicine $1781-788$.

Nobrega MA, Ovcharenko I, Afzal V \& Rubin EM 2003 Scanning human gene deserts for long-range enhancers. Science 302413.

Paralkar V \& Wistow G 1994 Cloning the human gene for macrophage migration inhibitory factor (MIF). Genomics 19 48-51.

Petrovsky N, Socha L, Silva D, Grossman AB, Metz C \& Bucala R 2003 Macrophage migration inhibitory factor exhibits a pronounced circadian rhythm relevant to its role as a glucocorticoid counter-regulator. Immunology and Cell Biology 81 137-143.

Petty RE, Southwood TR, Baum J, Bhettay E, Glass DN, Manners P, Cocco J, Suarez AM, Orozco AJ \& Prieur AM 1998 Revision of the proposed classification criteria for juvenile idiopathic arthritis: Durban 1997. Journal of Rheumatology 25 1991-1994.

Roger T, David J, Glauser MP \& Calandra T 2001 MIF regulates innate immune responses through modulation of Toll-like receptor 4. Nature 414 920-924.

Sakai Y, Masamune A, Satoh A, Nishihira J, Yamagiwa T \& Shimosegawa T 2003 Macrophage migration inhibitory factor is a critical mediator of severe acute pancreatitis. Gastroenterology 124 725-736.

Santos L, Hall P, Metz C, Bucala R \& Morand EF 2001 Role of macrophage migration inhibitory factor (MIF) in murine antigen-induced arthritis: interaction with glucocorticoids. Clinical and Experimental Immunology 123 309-314.

Stevens A, Ray D, Alansari A, Hajeer A, Thomson W, Donn R, Ollier WE, Worthington J \& Davis JR 2001 Characterization of a prolactin gene polymorphism and its associations with systemic lupus erythematosus. Arthritis and Rheumatism 44 2358-2366.

Subramanya HS, Roper DI, Dauter Z, Dodson EJ, Davies GJ, Wilson KS \& Wigley DB 1996 Enzymatic ketonization of 2-hydroxymuconate: specificity and mechanism investigated by the crystal structures of two isomerases. Biochemistry 35 792-802.

Sugimoto H, Suzuki M, Nakagawa A, Tanaka I \& Nishihira J 1996 Crystal structure of macrophage migration inhibitory factor 
from human lymphocyte at 2.1 A resolution. FEBS Letters 389 145-148.

Sugimoto H, Taniguchi M, Nakagawa A, Tanaka I, Suzuki M \& Nishihira J 1999 Crystal structure of human D-dopachrome tautomerase, a homologue of macrophage migration inhibitory factor, at 1.54 A resolution. Biochemistry 38 3268-3279.

Sun HW, Bernhagen J, Bucala R \& Lolis E 1996 Crystal structure at 2.6-A resolution of human macrophage migration inhibitory factor. PNAS 93 5191-5196.

Suzuki M, Sugimoto H, Nakagawa A, Tanaka I, Nishihira J \& Sakai M 1996 Crystal structure of the macrophage migration inhibitory factor from rat liver. Nature Structural Biology 3 259-266.

Taylor AB, Johnson WH Jr, Czerwinski RM, Li HS, Hackert ML \& Whitman CP 1999 Crystal structure of macrophage migration inhibitory factor complexed with (E)-2-fluoro-p-hydroxycinnamate at 1.8 A resolution: implications for enzymatic catalysis and inhibition. Biochemistry 38 7444-7452.

Waeber G, Thompson N, Chautard T, Steinmann M, Nicod P, Pralong FP, Calandra T \& Gaillard RC 1998 Transcriptional activation of the macrophage migration-inhibitory factor gene by the corticotropin-releasing factor is mediated by the cyclic adenosine $3^{\prime}, 5^{\prime}$ - monophosphate responsive element-binding protein CREB in pituitary cells. Molecular Endocrinology 12 698-705.

Weiser WY, Temple PA, Witek-Giannotti JS, Remold HG, Clark SC \& David JR 1989 Molecular cloning of a cDNA encoding a human macrophage migration inhibitory factor. PNAS $867522-7526$.

Yabunaka N, Nishihira J, Mizue Y, Tsuji M, Kumagai M, Ohtsuka Y, Imamura M \& Asaka M 2000 Elevated serum content of macrophage migration inhibitory factor in patients with type 2 diabetes. Diabetes Care 23 256-258.

Received 20 January 2004

Accepted 11 March 2004

Made available online as an

Accepted Preprint 22 March 2004 